\title{
Effects of apocynin on oxidative stress and expression of apoptosis-related genes in testes of diabetic rats
}

\author{
MINGCHAO LI, ZHUO LIU, LI ZHUAN, TAO WANG, SHUIMING GUO, \\ SHAOGANG WANG, JIHONG LIU and ZHANGQUN YE
}

\author{
Department of Urology, Tongji Hospital, Tongji Medical College, Huazhong University \\ of Science and Technology, Wuhan 430030, Hubei, P.R. China
}

Received March 15, 2012; Accepted July 13, 2012

DOI: $10.3892 / \mathrm{mmr} .2012 .1132$

\begin{abstract}
Reactive oxygen species (ROS) are important in the development of diabetic testicular dysfunction. Overproduction of ROS promotes the process of apoptosis, which shows that there is a crosstalk between oxidative stress and apoptosis. Recent research has suggested that NADPH oxidase is the main source of ROS. In this study, we investigated whether the NADPH oxidase inhibitor, apocynin, can improve diabetes-induced testicular dysfunction by suppressing oxidative stress. The streptozocin (STZ)-induced diabetic rats were administered apocynin, and the mRNA and protein expression of Bax, Bcl-2, p47 ${ }^{\text {phox }}$ and $\mathrm{p} 67^{\text {phox }}$ was examined by real-time PCR (RT-PCR) and western blot analysis. Production of ROS was measured by thiobarbituric acid reactive substances (TBARS) assay. Terminal-deoxynucleoitidyl transferase mediated nick end-labeling (TUNEL) assay was used to detect apoptosis and ELISA was used to detect total testosterone levels. The mRNA and protein expression of Bcl-2 was significantly reduced, and that of Bax, p47 ${ }^{\text {phox }}$ and $\mathrm{p} 67^{\text {phox }}$ was significantly increased in the diabetic rats compared to the control group. Apocynin significantly increased the expression of Bcl-2 and decreased the expression of Bax, $\mathrm{p} 47^{\text {phox }}$ and $\mathrm{p} 67^{\text {phox }}$ at both the mRNA and protein levels. The production of ROS and apoptotic cells significantly increased in the diabetic group compared to the control group. Apocynin significantly reduced the production of ROS and apoptotic cells and increased the total testosterone level. In conclusion, apocynin is capable of ameliorating testicular dysfunction.
\end{abstract}

\section{Introduction}

Diabetes mellitus (DM) is the most common metabolic disease (1). There is increasing evidence that diabetes is closely

Correspondence to: Dr Tao Wang or Dr Jihong Liu, Department of Urology, Tongji Hospital, Tongji Medical College, Huazhong University of Science and Technology, Wuhan 430030, Hubei, P.R. China

E-mail: twang@tjh.tjmu.edu.cn

E-mail:jhliu@tjh.tjmu.edu.cn

Key words: reactive oxygen species, apocynin, testicular dysfunction associated with male reproductive dysfunction. Compared with non-diabetic individuals, male diabetic patients showed an increased incidence of hypogonadism and infertility (2). Oxidative stress damage is regarded as the most influential harmcausing factor affecting testicular function (2-4). The increase in reactive oxygen species (ROS) causes non-specific changes in nucleic acid, protein and phospholipid levels, resulting in DNA, RNA and protein damage and alterations in antioxidant enzyme levels, which lead to cellular and tissue damage (1). Diabetes inhibits reproductive activity in experimental animals; for instance, the testicular function of diabetic rats is impaired, including reduced testicular weight, sperm count and sperm motility (5). Antioxidant vitamin $\mathrm{E}$ is capable of improving diabetes-induced free radical damage in testicular tissue (1).

A previous study showed that the apoptosis of testicular germ cells increases in diabetic mice, leading to the disruption of spermatogenesis (6). Apoptosis occurs in the testes of diabetic animals, but the mechanism of apoptosis has not yet been clarified (7). Apoptotic cell death is mediated by the activation of apoptotic signaling pathways, including the Bcl-2 family proteins. Bcl-2 and Bcl-xL suppress apoptotic cell death through anti-apoptotic function, whereas Bax and Bad promote apoptotic death through pro-apoptotic function (7).

The overproduction of ROS promotes the process of apoptosis by increasing caspase-3 activity and inhibiting Bcl-2 expression, which demonstrates that a crosstalk exists between oxidative stress and apoptosis (2).

Previous studies have indicated that NADPH oxidase is the main source of ROS, and that activated NADPH oxidase results in increased ROS production (8-10). ROS derived from NADPH oxidase play a potent role in initiating and accelerating the development of diabetic complications (11). NADPH oxidase is composed of the regulatory subunits, p67phox (phox, phagocyte oxidase), p47 $7^{\text {phox }}, \mathrm{p} 22^{\text {phox }}$ and $\mathrm{p} 40^{\text {phox }}$, and the catalytic subunit, gp91 ${ }^{\text {phox }}$. The active oxidase generates superoxide by transferring the electron from NADPH to oxygen (12).

Apocynin has been previously shown to effectively inhibit the increased NADPH oxidase activity in diabetic aortas and to restore changes in nitric oxide synthase (NOS) expression, thereby blocking the vicious cycle which results in diabetes-associated endothelial dysfunction (13). A recent study also showed that elevated activity of NADPH oxidase led to significant testicular damage, and that the antioxidant, 
strontium fructose 1,6-diphosphate (FDP-Sr), restored the testicular function (14).

The aim of this study was to examine whether testicular dysfunction and apoptosis under diabetic conditions can be ameliorated by the NADPH oxidase inhibitor, apocynin, by suppressing oxidative stress.

\section{Materials and methods}

Experimental animals. Tongji Hospital, Tongji Medical College, Huazhong University of Science (Wuhan, China) and the Technology Animal Care and Use Committee approved all procedures undertaken in the current study. Seven-week-old male Sprague-Dawley (SD) rats were obtained from Tongji Medical College, Huazhong University of Science and Technology. Diabetes in rats was induced by a single intraperitoneal injection of streptozocin (STZ) at a dose of $60 \mathrm{mg} / \mathrm{kg}$ in citrate buffer (50 mM sodium citrate, $\mathrm{pH} 4.5$ ), blood glucose levels in serum samples obtained from the tail vein of all rats were detected prior to diabetes induction and $72 \mathrm{~h}$ after intraperitoneal injection of STZ with a blood glucose meter (Johnson and Johnson, New Brunswick, NJ, USA). The rats with blood glucose concentrations $>11.1 \mathrm{mmol} / 1$ were accepted as being diabetic.

Eight weeks after the induction of diabetes, diabetic rats were randomly divided into 2 groups: the untreated group and the apocynin-treatment group $(16 \mathrm{mg} / \mathrm{kg})$. The treatment period was 4 weeks. Age-matched male SD rats were used as the control group.

At the end of the treatment period, the blood collected via cardiac puncture was allowed to clot and the serum was obtained by centrifugation at $1,500 \mathrm{x} g$ for $15 \mathrm{~min}$. Serum samples were stored at $-80^{\circ} \mathrm{C}$ until analysis. The testes were harvested after rats were sacrificed with an intraperitoneal overdose of pentobarbital.

Measurement of serum testosterone level. The serum testosterone level was detected using a rat testosterone ELISA kit (R\&D Systems, Inc., Minneapolis, MN, USA) according to the manufacturer's instructions.

Measurement of testicular mRNA expression. Total RNA was isolated from testicular tissue using TRIzol reagent (Invitrogen, Carlsbad, CA, USA) according to the manufacturer's instructions. cDNA was synthesized from $500 \mathrm{ng}$ of RNA using the PrimeScript ${ }^{\mathrm{TM}}$ RT reagent kit (Takara, Dalian, China) according to the manufacturer's instructions. Realtime PCR was carried out with a Stratagene real-time PCR system (Agilent Technologies, Inc., Santa Clara, CA, USA). The real-time PCR reactions were performed using SYBR Premix Ex Taq (Takara). The final volume of $25 \mu 1$ contained $2.0 \mu \mathrm{l}$ cDNA, $12.5 \mu \mathrm{l}$ SYBR Premix Ex Taq, $0.5 \mu \mathrm{l}(10 \mathrm{mM})$ of forward and reverse primers, $0.5 \mu \mathrm{l}$ ROX Reference Dye

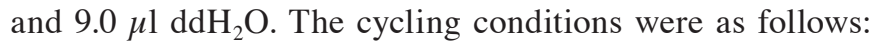
predenaturation at $95^{\circ} \mathrm{C}$ for $30 \mathrm{sec}$, followed by 40 cycles at $95^{\circ} \mathrm{C}$ for $5 \mathrm{sec}$ and $60^{\circ} \mathrm{C}$ for $30 \mathrm{sec}$. Immediately following amplification, melt curve protocols were performed to ensure that primer dimers and other non-specific products had been minimized or eliminated. As an endogenous reference and for normalization purposes, the level of mRNA expression for
Table I. Primer sequences for real-time quantitative polymerase chain reaction.

\begin{tabular}{|c|c|}
\hline Gene & Primers \\
\hline $\mathrm{p} 47^{\text {phox }}$ & F: 5'-GAGACATACCTGACGGCCAAAGA-3' \\
\hline p4 $7^{\text {phox }}$ & R: 5'-AGTCAGCGATGGCCCGATAG-3' \\
\hline p6 $67^{\text {phox }}$ & F: 5'-GAAAGCATGAAGGATGCCTGG-3' \\
\hline p6 $67^{\text {phox }}$ & R: 5'-ATAGCACCAAGATCACATCTCC-3' \\
\hline Bax & F: 5'-GTTACAGGGTTTCATCCAGG-3' \\
\hline Bax & R: 5'-CGTGTCCACGTCAGCAAT-3' \\
\hline $\mathrm{Bcl}-2$ & F: 5'-CGGGAGAACAGGGTATGA-3' \\
\hline $\mathrm{Bcl}-2$ & R: 5'-CAGGCTGGAAGGAGAAGAT-3' \\
\hline$\beta$-actin & F: 5'-AAGAGCTATGAGCTGCCTGA-3' \\
\hline$\beta$-actin & R: 5'-TACGGATGTCAACGTCACAC-3' \\
\hline
\end{tabular}

F, forward; R, reverse.

$\beta$-actin was measured. Relative quantification of the expression levels of each transcript for each group was calculated using the $2^{-\Delta \Delta \mathrm{Ct}}$ method. Using the non-diabetic control as the calibrator, the data of other groups were presented as the fold change in gene expression normalized to $\beta$-actin and relative to the non-diabetic control. The sequences of the PCR primers used are shown in Table I.

Measurement of testicular protein expression. Testicular tissues were homogenized in lysis buffer on ice. Protein was loaded on SDS-PAGE gel. The resolved proteins were transferred onto $0.2-\mu \mathrm{m}$ nitrocellulose membranes, and blots were blocked in $5 \%$ non-fat dried milk for $1 \mathrm{~h}$ at $37^{\circ} \mathrm{C}$ to saturate non-specific protein binding. The membranes were incubated overnight at a 1:500 dilution of polyclonal primary antibody (Santa Cruz Biotechnology, Inc., Santa Cruz, CA, USA). The membranes were then incubated with appropriate alkaline phosphatase-linked secondary antibodies (Proteintech Group, Inc., Chicago, IL, USA) for $1 \mathrm{~h}$ at $37^{\circ} \mathrm{C}$ and visualized using the BCIP/NBT Chromogen system (Covance Inc., Princeton, NJ, USA). $\beta$-actin was used as the internal control to standardize each sample with equal protein quantity. Protein expression was quantified by computer-assisted densitometry with the use of the Gel Pro version 4.0 software (Media Cybernetics, Georgia, MD, USA).

Thiobarbituric acid reactive substances (TBARS) assay. TBARS measures a family of lipid peroxidation products and is a major indicator of oxidative stress (8). Frozen testicular tissue was pulverized and resuspended in phosphate-buffered saline. TBARS levels were analyzed using the TBARS assay kit (Cayman Chemical Company, Ann Arbor, MI, USA) according to the manufacturer's instructions. In this assay, a malondialdehyde (MDA) standard curve was constructed, and TBARS levels were expressed in terms of MDA equivalents and normalized to the wet weight of testicular tissue.

Detection of apoptosis. The apoptotic cells were detected by terminal deoxynucleotidyl transferase-mediated dUTP nick 
Table II. Weight and blood glucose in control and streptozocin (STZ) diabetic rats.

$$
\text { Control }(\mathrm{n}=10) \quad \text { Diabetes }(\mathrm{n}=10)
$$

Diabetes + apocynin $(\mathrm{n}=10)$

\begin{tabular}{|c|c|c|c|}
\hline \multicolumn{4}{|c|}{ Weight (g) } \\
\hline Initial & $272.7 \pm 6.9$ & $273.4 \pm 6.8$ & $274.3 \pm 6.5$ \\
\hline Final & $403.0 \pm 10.0^{\mathrm{a}}$ & $246.4 \pm 7.0^{\mathrm{a}}$ & $245.5 \pm 6.9^{\mathrm{a}}$ \\
\hline \multicolumn{4}{|c|}{ Blood glucose (mM) } \\
\hline Initial & $5.5 \pm 0.50$ & $5.6 \pm 0.45$ & $5.6 \pm 0.46$ \\
\hline Final & $5.7 \pm 0.39$ & $30.5 \pm 1.20^{\mathrm{a}}$ & $30.2 \pm 1.20^{\mathrm{a}}$ \\
\hline
\end{tabular}

Data are expressed as means $\pm \mathrm{SD}$. ${ }^{\mathrm{a}} \mathrm{P}<0.05$, compared with the initial level. $\mathrm{n}=$ number of analyzed samples.

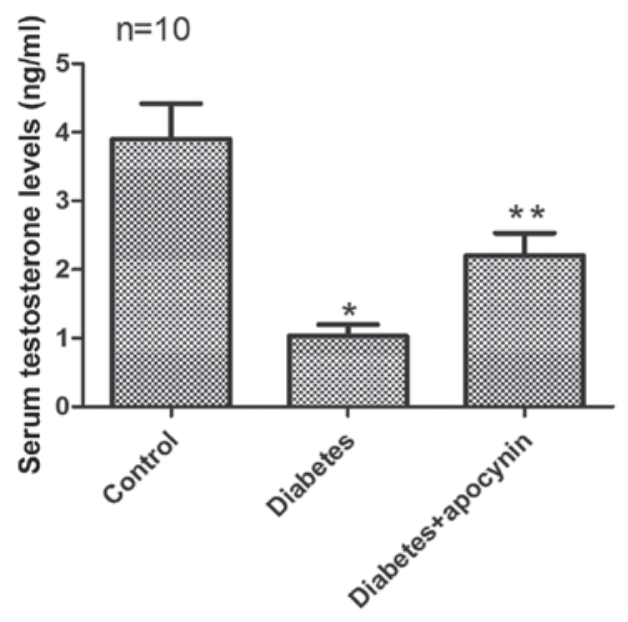

Figure 1. Serum testosterone levels significantly declined in diabetic rats compared with the control group. Serum testosterone levels of diabetic rats treated with apocynin significantly increased. ${ }^{*} \mathrm{P}<0.05$ vs. the control group, ${ }^{* *} \mathrm{P}<0.05$ vs. the diabetes group.

end-labeling (TUNEL) assay with the ApopTag peroxidase in situ apoptosis detection kit (Chemicon International, Inc., Temecula, CA, USA), as described in a previous study (15). Testicular tissue was fixed in $10 \%$ formalin, embedded in paraffin and sectioned at $5 \mu \mathrm{m}$. The slides were de-paraffinized and rehydrated, and treated with proteinase $\mathrm{K}(20 \mathrm{mg} / \mathrm{l})$ for $15 \mathrm{~min}$, then treated with $3 \%$ hydrogen peroxide for $5 \mathrm{~min}$ to inhibit endogenous peroxidase and incubated with the TUNEL reaction mixture containing terminal deoxynucleotidyl transferase (TdT) and digoxigenin-11-dUTP at $37^{\circ} \mathrm{C}$ for $1 \mathrm{~h}$. The TdT reaction was performed in a humidified chamber at $37^{\circ} \mathrm{C}$ for $1 \mathrm{~h}$, and then 3,3-diaminobenzidine (DAB) chromogen was used. Hematoxylin was used as counterstaining.

Statistical analysis. Data were expressed as the means \pm SD and analyzed by one-way analysis of variance (ANOVA). Post hoc analysis was carried out by Student Newman-Keuls or Dunnett's tests as appropriate. $\mathrm{P}<0.05$ was considered to indicate a statistically significant difference.

\section{Results}

General parameters. The final mean blood glucose concentration of STZ-diabetic rats significantly increased compared with that

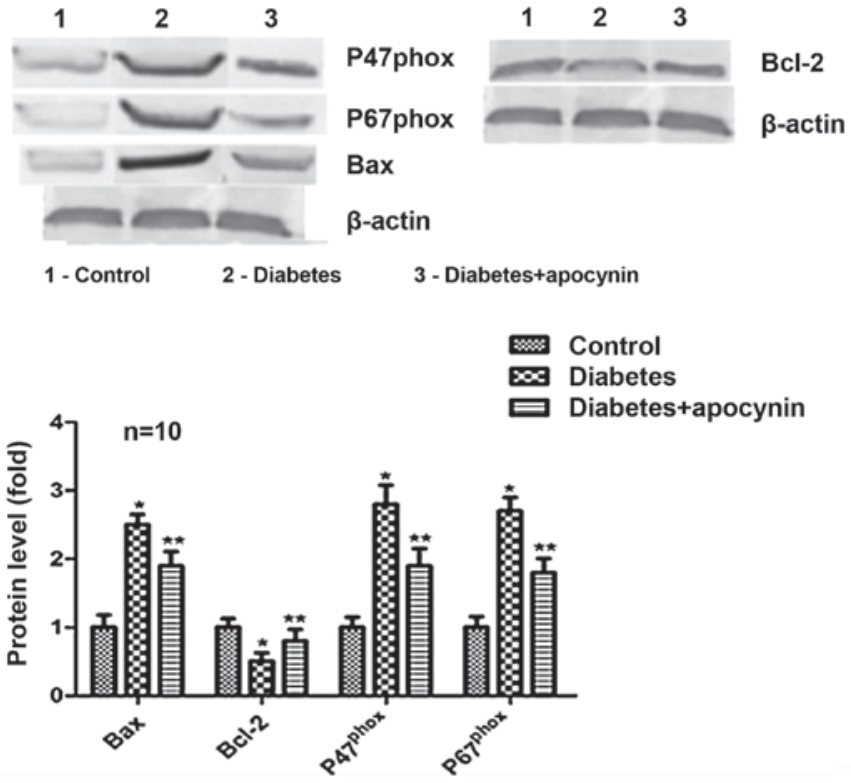

Figure 2. Protein expression of Bcl-2, Bax and the NADPH oxidase subunits, $\mathrm{p} 47^{\mathrm{phox}}$ and $\mathrm{p} 67^{\mathrm{phox}}$, in rat testes. Protein expression was normalized to that of $\beta$-actin. ${ }^{*} \mathrm{P}<0.05$ vs. the control group; ${ }^{* *} \mathrm{P}<0.05$ vs. the diabetes group.

of initial mean blood glucose concentration, and apocynin treatment for 4 weeks did not significantly affect the blood glucose concentration in diabetic rats. The final mean bodyweight of the diabetic rats significantly decreased compared with that of initial mean bodyweight. Apocynin treatment did not significantly change the body weight of diabetic rats (Table II).

Total testosterone level. Serum testosterone levels in rats from the diabetic group were significantly reduced compared with the control group $(\mathrm{P}<0.05)$ (Fig. 1). Apocynin treatment significantly increased the testosterone level in diabetic rats $(\mathrm{P}<0.05)$ (Fig. 1).

Protein expression. Western blot analysis revealed that $\mathrm{Bcl}-2$ protein expression was significantly decreased in rat testes of the diabetic group $(\mathrm{P}<0.05)$ (Fig. 2), while the expression of Bax, $4^{4} 7^{\text {phox }}$ and $\mathrm{p} 67^{\text {phox }}$ significantly increased compared with the control group $(\mathrm{P}<0.05)$ (Fig. 2). Treatment of diabetic rats with apocynin significantly suppressed all down- and/or upregulation. 

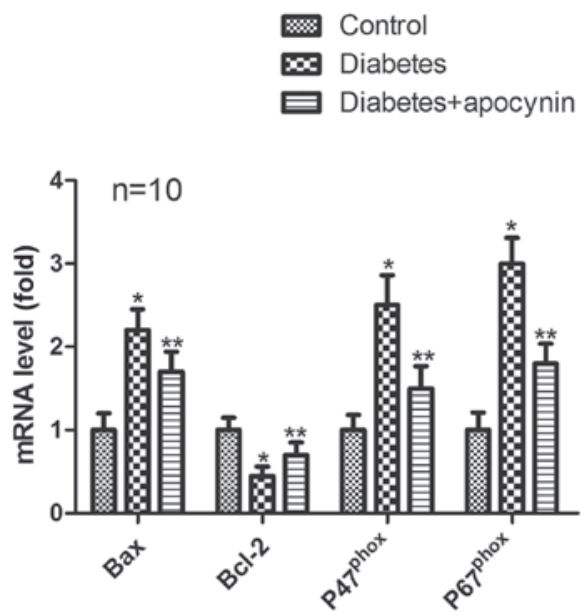

Figure 3. mRNA expression of Bcl-2, Bax and the NADPH oxidase subunits, p47 $7^{\text {phox }}$ and $p 67^{\text {phox }}$ in rat testes. mRNA expression was normalized to that of $\beta$-actin. ${ }^{*} \mathrm{P}<0.05$ vs. the control group; ${ }^{* *} \mathrm{P}<0.05$ vs. the diabetes group.

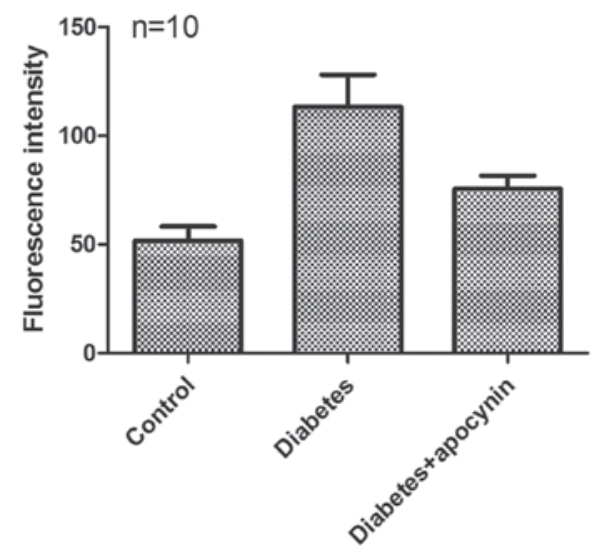

Figure 4. TBARS levels in rat testicular tissue. Statistical results showed that TBARS levels were increased in diabetic rats compared with that of control rats. Apocynin effectively reduced TBARS levels in the testis of diabetic rats. ${ }^{~} \mathrm{P}<0.05$ vs. the control group; ${ }^{* *} \mathrm{P}<0.05$ vs. the diabetes group. TBARS, thiobarbituric acid reactive substances.
A

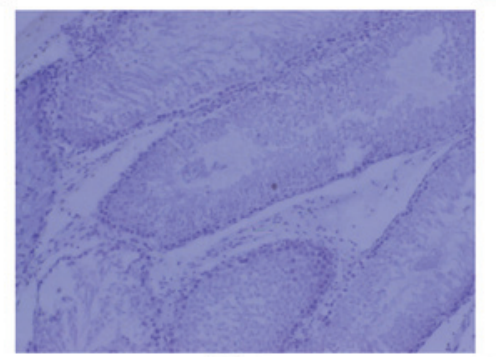

$\mathrm{C}$

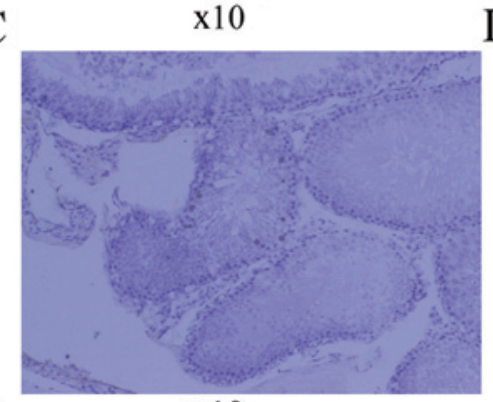

E

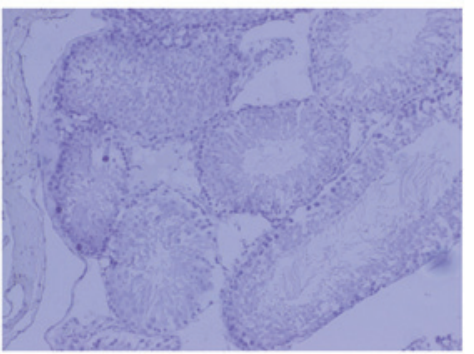

$\mathrm{x} 10$
B

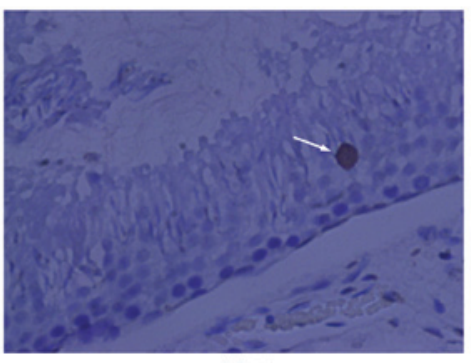

$\mathrm{D}$

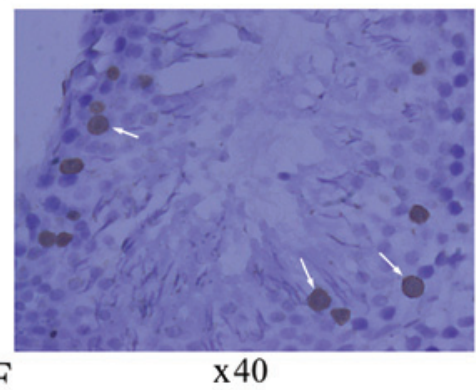

F

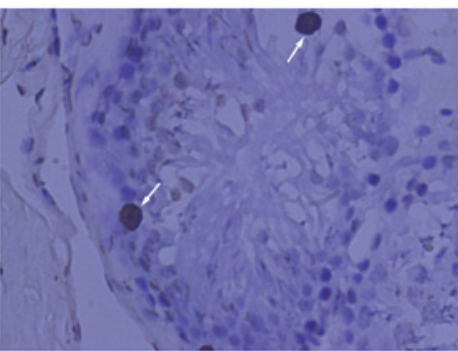

x 40

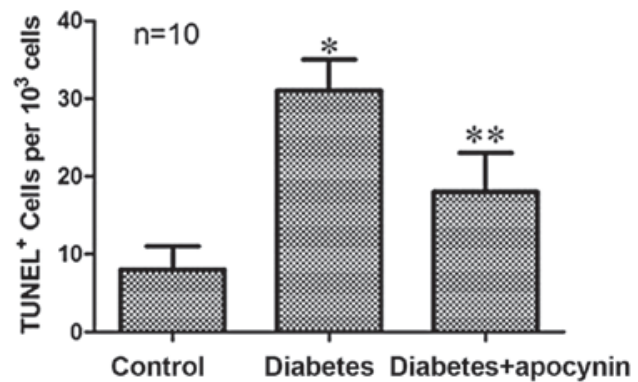

Figure 5. Testicular apoptotic cells were detected with TUNEL staining. Representative TUNEL staining images were presented for (A and B) control, $(\mathrm{C}$ and $\mathrm{D})$ diabetes and (E and F) diabetes + apocynin. The arrows show the apoptotic cells. The testicular apoptotic cells significantly increased in diabetic rats compared with the control group $(\mathrm{P}<0.05)$. Treatment of diabetic rats with apocynin significantly decreased apoptotic cells $(\mathrm{P}<0.05)$. ${ }^{*} \mathrm{P}<0.05$ vs. the control group; ${ }^{* *} \mathrm{P}<0.05$ vs. the diabetes group. Magnification, $\mathrm{x} 10$ and $\mathrm{x} 40$. TUNEL, Terminal-deoxynucleoitidyl transferase mediated nick end-labeling. 
mRNA expression. In the testes of diabetic rats, mRNA expression of $\mathrm{Bcl}-2$ was significantly decreased $(\mathrm{P}<0.05)$ (Fig. 3), whereas mRNA expression of Bax, p47 ${ }^{\text {phox }}$ and $\mathrm{p} 67^{\text {phox }}$ significantly increased compared with control group $(\mathrm{P}<0.05)$ (Fig. 3). Treatment of diabetic rats with apocynin significantly suppressed all down- and/or upregulation $(\mathrm{P}<0.05)$ (Fig. 3).

Production of ROS. A significant increase in the TBARS level was observed in the testes of the diabetic rats when compared to those of control rats $(0.359 \pm 0.019$ vs. $0.251 \pm 0.02 \mathrm{nmol}$ $\mathrm{MDA} / \mathrm{mg}$ wet tissue, respectively) $(\mathrm{P}<0.05)$ (Fig. 4). Treatment with apocynin effectively reduced the TBARS level in the testes of diabetic rats $(0.302 \pm 0.018 \mathrm{nmol} \mathrm{MDA} / \mathrm{mg}$ wet tissue $)$ $(\mathrm{P}<0.05)$ (Fig. 4).

Apocynin decreases apoptosis. The testicular apoptotic cells significantly increased in rats of the diabetic group compared with the control group $(\mathrm{P}<0.05)$ (Fig. 5), as evaluated by TUNEL staining. Treatment of diabetic rats with apocynin significantly decreased apoptotic cell numbers $(\mathrm{P}<0.05)$ (Fig. 5).

\section{Discussion}

The present study demonstrated that serum testosterone levels and testicular apoptotic cells of diabetic rats significantly declined, and testicular apoptotic cells of diabetic rats significantly increased, which was associated with enhanced oxidative stress and apoptosis in testes. The NADPH oxidase inhibitor apocynin significantly ameliorated testicular dysfunction by its antioxidant activity.

Apocynin was used at a dose of $16 \mathrm{mg} / \mathrm{kg}$ per day in this study, with reference to a previous study on diabetic neuropathy reporting that a daily dose of $100 \mathrm{mg} / \mathrm{kg}$ was no more effective than $15 \mathrm{mg} / \mathrm{kg}$ in preventing neuropathy and reducing nerve blood flow in diabetic rats (12).

Diabetes has been reported to cause testicular dysfunction. Diabetes results in certain changes in seminiferous tubules, including increased tubular wall thickness, severe germ-cell depletion and Sertoli cell vacuolization, as well as reduced testicular volumes, semen volume and numbers of Leydig cells and their spontaneous secretion of testosterone (16). Oxidative stress plays a direct role in the pathogenesis of various diabetic complications, which is one of the major causes of testicular dysfunction $(1,17)$. Hyperglycemia is capable of increasing free radical formation and reducing endogenous antioxidant capacity, leading to enhanced oxidative stress in testicular tissue (1). Previous studies have suggested that diabetic testicular lesions involve significant oxidative stress (2). Overproduction of ROS results in mitochondrial damage and lipid peroxidation in germ and Leydig cells, which lead to dysfunction of testicular spermatogenesis and steroidogenesis (2). Our data showed that ROS production significantly increased and the testosterone level significantly decreased in diabetic testicular tissue, which confirmed the findings of previous studies $(1,2)$.

A recent study suggested that NADPH oxidase be considered as an important source of ROS in both physiological and pathophysiological conditions (11). In another recent study, it was demonstrated that NADPH oxidase p22, p47 and p67 subunits were significantly increased in diabetic testes rela- tive to normal testes (14). In agreement with these results, the results from our study demonstrated that NADPH oxidase p47 and p67 subunits were significantly increased in diabetic testes.

Other studies have reported a significant increase in the apoptotic cell death in the testes of diabetic rats $(2,5,18)$. There is increasing evidence showing that excessive ROS production triggers an apoptosis cascade through the phosphorylation of JNK and activation of Bax (18), and by activating caspase, regulating the expression of Bcl-2 family proteins (19). Moreover, the decreased production of testosterone may also promote germ cell apoptosis (20). In the present study, increased ROS and decreased production of testosterone may constitute the major reasons for testicular apoptosis, which confirms the findings of previous studies (2,18-20).

Previous studies have shown that antioxidant vitamin $\mathrm{E}$ and $\mathrm{C}$ relieve testicular injury by suppressing oxidative stress (1). Antioxidant FDP-Sr and endothelin type A receptor antagonist attenuated cell death by suppressing oxidative stress $(2,14,19)$. NADPH oxidase is the main source of ROS, and elevated activity of NADPH oxidase results in increased ROS production (8-10). In our study, the NADPH oxidase inhibitor, apocynin, significantly reduced ROS production and cell death by suppressing oxidative stress, which was consistent with the results from a previous study (14).

In conclusion, our results clearly demonstrate that the increased rate of testicular cell death by apoptosis in STZ-induced diabetic rats is driven by excessive ROS production, and that apoptosis in testicular tissues can be ameliorated by the NADPH oxidase inhibitor, apocynin, by suppressing the excessive production of ROS.

\section{References}

1. Aybek H, Aybek Z, Rota S, Sen N and Akbulut M: The effects of diabetes mellitus, age, and vitamin $\mathrm{E}$ on testicular oxidative stress. Fertil Steril 90: 755-760, 2008.

2. Tang XY, Zhang Q, Dai DZ, Ying HJ, Wang QJ and Dai Y: Effects of strontium fructose 1,6-diphosphate on expression of apoptosis-related genes and oxidative stress in testes of diabetic rats. Int J Urol 15: 251-256, 2008.

3. Shrilatha B and Muralidhara: Early oxidative stress in testis and epididymal sperm in streptozotocin-induced diabetic mice: its progression and genotoxic consequences. Reprod Toxicol 23: 578-587, 2007.

4. Boujbiha MA, Hamden K, Guermazi F, Bouslama A, Omezzine A, Kammoun A and El Feki A: Testicular toxicity in mercuric chloride treated rats: association with oxidative stress. Reprod Toxicol 28: 81-89, 2009.

5. Kosova B, Cetintaş VB, Yavaşoğlu A, Altay B and Aktuğ H: From a molecular biological viewpoint, does endothelin type A receptor antagonist therapy reduce diabetes-induced testicular damage in rats? Urology 77: 250.e7-13, 2011.

6. Sainio-Pöllänen S, Henriksén K, Parvinen M, Simell O and Pöllänen P: Stage-specific degeneration of germ cells in the seminiferous tubules of nonobese diabetic mice. Int J Androl 20: 243-253, 1997.

7. Koh PO: Streptozotocin-induced diabetes increases the interaction of $\mathrm{Bad} / \mathrm{Bcl}-\mathrm{xL}$ and decreases the binding of $\mathrm{pBad} / 14-3-3$ in rat testis. Life Sci 81: 1079-1084, 2007.

8. Jin L, Lagoda G, Leite R, Webb RC and Burnett AL: NADPH oxidase activation: a mechanism of hypertension-associated erectile dysfunction. J Sex Med 5: 544-551, 2008.

9. Jin L and Burnett AL: NADPH oxidase: recent evidence for its role in erectile dysfunction. Asian J Androl 10: 6-13, 2008.

10. Cai H, Griendling KK and Harrison DG: The vascular NAD(P)H oxidases as therapeutic targets in cardiovascular diseases. Trends Pharmacol Sci 24: 471-478, 2003. 
11. Taye A, Saad AH, Kumar AH and Morawietz H: Effect of apocynin on NADPH oxidase-mediated oxidative stress-LOX-1eNOS pathway in human endothelial cells exposed to high glucose. Eur J Pharmacol 627: 42-48, 2010.

12. Cotter MA and Cameron NE: Effect of the NAD(P)H oxidase inhibitor, apocynin, on peripheral nerve perfusion and function in diabetic rats. Life Sci 73: 1813-1824, 2003.

13. Olukman M, Orhan CE, Celenk FG and Ulker S: Apocynin restores endothelial dysfunction in streptozotocin diabetic rats through regulation of nitric oxide synthase and NADPH oxidase expressions. J Diabetes Complications 24: 415-423, 2010.

14. Xu M, Dai DZ, Zhang Q, Cheng YS and Dai Y: Upregulated NADPH oxidase contributes to diabetic testicular complication and is relieved by strontium fructose 1,6-diphosphate. Exp Clin Endocrinol Diabetes 118: 459-465, 2010.

15. Zhao Y, Tan Y, Dai J, et al: Exacerbation of diabetes-induced testicular apoptosis by zinc deficiency is most likely associated with oxidative stress, p38 MAPK activation, and p53 activation in mice. Toxicol Lett 200: 100-106, 2011.
16. Unlüçerçi Y, Bekpinar S and Koçak H: Testis glutathione peroxidase and phospholipid hydroperoxide glutathione peroxidase activities in aminoguanidine-treated diabetic rats. Arch Biochem Biophys 379: 217-220, 2000.

17. Shrilatha B and Muralidhara: Occurrence of oxidative impairments, response of antioxidant defences and associated biochemical perturbations in male reproductive milieu in the Streptozotocin-diabetic rat. Int J Androl 30: 508-518, 2007.

18. Koh PO. Streptozotocin-induced diabetes increases apoptosis through JNK phosphorylation and Bax activation in rat testes. J Vet Med Sci 69: 969-971, 2007.

19. Kaushal N and Bansal MP: Dietary selenium variation-induced oxidative stress modulates CDC2/cyclin B1 expression and apoptosis of germ cells in mice testis. J Nutr Biochem 18: 553-564, 2007.

20. Boekelheide K, Fleming SL, Johnson KJ, Patel SR and Schoenfeld HA: Role of Sertoli cells in injury-associated testicular germ cell apoptosis. Proc Soc Exp Biol Med 225: 105-115, 2000 . 